\section{The economic burden of hypertension, heart failure, myocardial infarction, and atrial fibrillation in Mexico}

\section{La carga económica de cuatro condiciones cardiacas en México: hipertensión; insuficiencia cardiaca; infarto de miocardio y fibrilación auricular}

Heart conditions impose physical, social, financial and health related quality of life limitations on individuals. These conditions result in an economic burden and impact on society due to expenditures on health care treatment, productivity losses from employment impacts, costs of providing formal and informal care, and lost wellbeing. Circulatory diseases presently represent the biggest health burden world-wide, accounting for over 17 million deaths every year; this represents half of all non-communicable disease deaths. ${ }^{1}$

We conducted a cost-of-illness analysis to assess the economic impact of four heart conditions in Mexico in 2015: hypertension (HTN), myocardial infarction (MI), atrial fibrillation (AF) and heart failure (HF). These conditions were considered noting the increasing prevalence and impacts of these conditions, ${ }^{1}$ and the study's ability to provide a common framework to assess their impact, allowing both the health costs and broader economic impacts to be assessed. Noting that new methods will need to be devised to address these conditions in the future, both from an access and equality perspective, the study also analyzed the cost effectiveness of two interventions for HF: telemedicine (TM) and structured telephone support (STS) to assess whether alternative models of care can lead to improved outcomes.

A standard cost of illness framework was used to assess the costs associated with the four conditions in 2015. The analysis assessed the prevalence and (in the case of myocardial infarction) incidence of the conditions, the associated expenditures on health care treatment, productivity losses from reduced employment, costs of providing formal and informal care, and lost wellbeing. The analysis was informed by a targeted literature review, data scan and modelling. All inputs and methods were validated by consulting nine clinicians and other stakeholders in Mexico. The cost-effectiveness analysis was based on a meta-analysis and economic evaluation of post-discharge programs in patients with heart failure, assessed from the perspective of the Instituto Mexicano del Seguro Social.

Health system expenditures were estimated based on the proportion of total health expenditure spent treating individual health conditions in Mexico, ${ }^{2}$ adjusted for the number of admissions and the average length of stay for the four conditions in Mexico ${ }^{3}$ and a cost loading per person per day in hospital, based on the cost of treating each of these conditions ${ }^{4}$ (see Appendix for further information).
Consistent with the 'full or near-full employment' criterion, ${ }^{\mathrm{b}}$ a human capital approach to the estimation of productivity losses was adopted. Calculations involving productivity losses were based on employment rates by age-gender groups. It was assumed that those with heart conditions were, in the absence of the condition, as likely to be employed as others in their corresponding age-gender group. Forgone wage income was based on wage data for Mexico. ${ }^{5}$ Absenteeism was associated with all of the conditions. For HF it was estimated as 12.66 days for those with New York Heart Association (NYHA) class III/IV and 3.04 days per year for those with NYHA I/II. ${ }^{6}$ Absenteeism was estimated as 3.03 days per year ${ }^{6}$ for HTN, 75 days per year for those admitted to hospital ${ }^{7}$ with $\mathrm{MI}$, and 2.1 days per year ${ }^{8}$ for AF. Reduced employment participation, where individuals are no longer able to be employed due to their condition, was identified for both HF and MI, but not AF or HTN. For $\mathrm{HF}$, there was a $13 \%$ lower employment participation rate (based on those with coronary heart disease). ${ }^{9}$ The study also showed increased withdrawal of unemployed people from the labour force, especially those aged below 60 years and those engaged in manual work. For MI, there was a $21 \%$ lower employment participation (based on those with acute coronary syndrome (ACS) five years after an event). ${ }^{10}$ As the lower employment participation rates in both the coronary heart disease and ACS studies were based on populations in developed countries these rates were adjusted by the observed rates of reduced employment participation for those with disability in Europe and Latin America, as reported by the Organisation for Economic Co-operation and Development (OECD). Forgone income due to premature death was based on mortality statistics for each condition and the otherwise expected life expectancy according to WHO life tables (see Appendix for further information).

The four heart conditions were estimated to affect approximately 20.5 million people in Mexico, $25.6 \%$ of the adult $^{\mathrm{C}}$ population. HTN had the highest prevalence of the four conditions, followed by HF. After adjusting for comorbidities, heart conditions were conservatively estimated to result in a financial cost of 96.4 billion pesos $(6.1$ billion USD) in 2015 in Mexico. Of this, approximately $46 \%$ was the health system cost (Table 1). In 2015, the burden of these four conditions comprised approximately $4 \%$ of total national healthcare expenditure.

Myocardial infarction imposes the greatest financial cost ( 39.0 billion pesos/2.5 billion USD), followed by heart failure (27.0 billion pesos/1.7 billion USD), hypertension ( 22.7 billion pesos/1.5 billion USD) and, finally, atrial fibrillation (8.4 billion pesos/532 million USD). In addition, the heart conditions included impose a substantial wellbeing loss. Of the 1.63 million disability adjusted life years (DALYs), adjusted for comorbidities, there are 902,081 healthy years lost

\footnotetext{
b The ILO reports the unemployment rate for Mexico at $4.9 \%$ in 2014 (the most recent year it was reported).

c Percentage reflects the evidence from studies among populations aged 20 years and over.
} 
Table 1 Financial cost of four heart conditions in Mexico, 2015 (millions of pesos).

\begin{tabular}{|c|c|c|c|c|c|c|}
\hline Category & $\mathrm{HF}$ & MI & $\mathrm{AF}$ & HTN & $\begin{array}{l}\text { Total } \\
\text { (unadjusted) }\end{array}$ & $\begin{array}{l}\text { Total (adjusted for } \\
\text { comorbidities) }^{c}\end{array}$ \\
\hline \multirow[t]{2}{*}{ Health system costs } & 7556 & 22,903 & 8111 & 5385 & 43,955 & 43,955 \\
\hline & $28 \%$ & $59 \%$ & $97 \%$ & $24 \%$ & $45 \%$ & $46 \%$ \\
\hline \multirow[t]{2}{*}{ Productivity losses } & 19,457 & 16,145 & 246 & 17,316 & 53,164 & 52,441 \\
\hline & $72 \%$ & $41 \%$ & $3 \%$ & $76 \%$ & $55 \%$ & $54 \%$ \\
\hline \multirow[t]{2}{*}{ Income forgone by individuals ${ }^{a}$} & 8259 & 11,874 & 143 & 7731 & 28,008 & 27,611 \\
\hline & $31 \%$ & $30 \%$ & $2 \%$ & $34 \%$ & $29 \%$ & $29 \%$ \\
\hline \multirow[t]{2}{*}{ Income forgone by businesses ${ }^{a}$} & 848 & 1050 & 73 & 7983 & 9954 & 9725 \\
\hline & $3 \%$ & $3 \%$ & $1 \%$ & $35 \%$ & $10 \%$ & $10 \%$ \\
\hline \multirow[t]{2}{*}{ Opportunity cost of informal care by family/friends } & 7155 & 631 & & & 7786 & 7774 \\
\hline & $26 \%$ & $2 \%$ & & & $8 \%$ & $8 \%$ \\
\hline \multirow[t]{2}{*}{ Tax revenue forgone by government ${ }^{\mathrm{b}}$} & 3194 & 2591 & 30 & 1602 & 7416 & 7332 \\
\hline & $12 \%$ & $7 \%$ & $0 \%$ & $7 \%$ & $8 \%$ & $8 \%$ \\
\hline Total cost (million pesos) & 27,013 & 39,048 & 8357 & 22,701 & 97,119 & 96,395 \\
\hline
\end{tabular}

a The result from absenteeism, reduced employment participation, and premature mortality.

b Due to reduced income of individuals with heart conditions and their carers.

c Comorbidities totals do not sum to the total of the individual conditions as one person can have more than one condition and the interaction between conditions causes the total estimate of the four conditions together to vary.

Table 2 Cost effectiveness of potential remote patient monitoring for heart failure in Mexico.

\begin{tabular}{llll}
\hline & SC & TM & STS \\
\hline Total costs (pesos) & 169,971 & 432,4890 & 422,164 \\
Total QALYs & 3.99 & 5.91 & 5.63 \\
Net monetary benefit & 930,090 & $1,194,500$ & $1,127,625$ \\
Incremental costs (pesos) & & 262,518 & 252,193 \\
Incremental QALYS & & 1.91 & 1.63 \\
Incremental cost (pesos) per QALY & & 137,232 & 154,466 \\
Incremental net monetary benefit & & 264,410 & 197,535 \\
\hline
\end{tabular}

due to disability (YLD) and over 723,306 years of life lost due to premature mortality (YLL).

A Markov model was constructed in TreeAge Pro@2015 to evaluate the cost effectiveness of STS and TM compared with usual care for a hypothetical cohort of patients discharged in the last 28 days following HF related hospitalizations. The model considered two different permanent health states, 'alive at home' and 'dead' as well as two temporary health states for 'hospitalized due to HF' and 'hospitalized for all other causes'. Over the 30year time horizon, the estimated discounted cumulative costs for the TM and STS interventions were 262,518 and 252,193 pesos higher than standard care (SC) respectively, but generated an additional 1.91 and 1.63 QALYs, respectively. This resulted in an estimated incremental cost effectiveness ratio (ICER) of 137,232 pesos/QALY and 154,466 pesos/QALY for TM and STS respectively compared to SC (Table 2), noting a willingness to pay (WTP) threshold of 137,727-413,181 pesos/QALY, which is based on one to three times the GDP per capita of Mexico. ${ }^{2}$ The incremental net monetary benefit was 264,410 pesos for TM vs SC and 197,535 pesos for STS vs SC (see Appendix for further information).

\section{Conclusions}

Heart conditions impose substantial loss of wellbeing and financial costs in Mexico and should be a public health priority. Telemedicine and structured telephone support are cost effective interventions for achieving improvements in the management of heart failure.

\section{Financing}

The study was supported by funding from the Novartis Group. The authors are solely responsible for its content.

\section{Conflict of interest}

The authors declare no conflict of interest.

\section{Acknowledgements}

The authors at Deloitte Access Economics designed the study, collected data, performed analysis and wrote the ini- 
tial draft of the manuscript. All authors read, commented on, and approved the final manuscript.

\section{Appendix.}

\section{Epidemiological data}

Whenever possible, Mexico specific rates were used and regional or other country estimates were only used only in the case where age group and population specific estimates were not available. Mortality was based on deaths by ICD-10 code from Instituto Nacional de Estadistica y Geografia to produce rates by age group. Identified rates were applied to population projections from the United Nations World Population Prospects.

\section{Loss of wellbeing}

Lost wellbeing - measured in DALYs - from the four heart conditions, in comparison to being in full health, was estimated based on prevalence and mortality calculations from the epidemiological data, using 'burden of disease' methodology. This methodology was developed originally by the World Bank, World Health Organization (WHO), Harvard University and other stakeholders. Disability weights were based on the WHO Global Burden of Disease studies as Mexico specific weights were not identified. These were then multiplied by the prevalence estimates to identify the years lost to disability for 2015. Years lost to life were based on reported mortality for each condition.

\section{Health system costs}

Total health expenditure was based on health expenditure as a share of GDP for Mexico, less the 'collective health care (prevention, health administration and health insurance)' cost share provided by the OECD for Mexico. To estimate the cost associated with each condition, hospital data using total admissions and average length of stay data from Mexico was used for each condition to yield the total number of bed days for each condition (categories included 'hypertensive diseases', 'myocardial infarction', 'conduction disorders and cardiac arrhythmias' (with a proportion estimated to be AF based on data from Minsalud in Colombia, due to a lack of Mexico specific information) and 'heart failure' which is compared to the total bed days provided in the health system. These proportions were then combined with a cost loading per person per day to incorporate the cost of treating each condition relative to non-cardiovascular conditions (based on Brazilian health system data, due to a lack of cost data in other health systems across Latin America). This method allowed condition specific loadings to be developed reflecting the differing costs associated - and reflecting the complexity and type of care required. The combined result provided the cost of treating the condition as a share of total health expenditure, which is then multiplied by total health expenditure to estimate the total impact.

This method allows us to most appropriately reflect the impacts based on the number, length of stay and cost intensity of each condition for Mexico specifically. However, data on condition-specific health expenditures are not available for other components of the health system (e.g. primary care). Accordingly, each condition's share of total health system expenditure was assumed to be the same as its share of total hospital expenditure.

\section{Productivity losses}

For absenteeism losses, it was assumed that that $46 \%$ of time off work for people of working age across all conditions can be taken as sick leave, representing a cost to employers, and the remaining $54 \%$ was unpaid (based on the proportion in informal employment), representing a loss to individuals and government through the associated forgone tax revenue. Employment rates and the average weekly wage for men and women were based on data for Mexico from the International Labour Organization.

For mortality costs, the anticipated number of years of life left to live (based on WHO life tables) by the deceased individual was multiplied first by employment rates and then by the average weekly wage for men and women respectively. The productivity discount rate for future earnings was $5.25 \%$ based on the difference between wage growth and inflation (using the annualized average for both over the past five years, as 2015 data was not available when the study was conducted). The present value of future wages was based on the five-year average real growth rate.

Informal care costs were identified for both HF and MI. For HF, each individual was provided an estimated $6.7 \mathrm{~h}$ of informal care per week. While there are a variety of sources for this parameter, the study chosen was the most robust methodologically and provided a similar estimate to what could be derived from a study in Latin America. For MI, based on a study of coronary heart disease patients, informal care hours were estimated to be $279 \mathrm{~h}$ per year per patient.

The forgone informal care wage was constructed from data from a Mexican time use survey. The number of hours spent caring for individuals over 60 years old by men and women (65\% women and $35 \%$ men) was used to weight average wages for men and women. The assumed fraction of individuals providing care who, in the absence of the heart condition, would be employed was based on a representative fraction from a Spanish based study, which was considered to be similar to the Latin American population in its demographic and cultural characteristics. Only the marginal increase in carer hours is attributed to the cost, rather than the total amount of care hours since, as individuals age, they frequently require care for a variety of reasons.

Taxation revenue forgone was based on the average income tax rate for a single individual and the average indirect tax rate according to the OECD. The estimated income tax liability was applied to the estimated total value of forgone earnings to determine the value of taxation lost. An adjustment was also applied for the number working in the 'informal economy' which is likely to reduce the taxation revenue collected. Exchange rates between USD and the local currency were based on the average of the 
daily exchange rates from the International Monetary Fund from January 2015 to November 2015.

\section{Comorbidities}

As multiple conditions could affect one person simultaneously, the total cost of the four conditions was estimated by identifying literature that estimated the rates at which individuals had two or more of the conditions. The literature alone, however, does not present estimates for individuals with three or more conditions simultaneously so did not ensure completely consistent estimates. Where literature did not outline the concomitant rates between each of the four conditions, the sources were extrapolated until all combinations were derived.

\section{Cost effectiveness analysis}

To undertake the analysis, a targeted literature review was carried out to identify either published cost effectiveness studies which could be adapted to the Mexican context, or literature which could inform the design of, and inputs to, a cost effectiveness model. The review identified a relatively recent network meta-analysis and cost effectiveness analysis of TM and STS programs after discharge in patients with $\mathrm{HF}$, conducted by the National Institute for Health Research in 2013. This study was therefore used as the basis for a cost effectiveness analysis of STS and TM from the perspective of the Instituto Mexicano del Seguro Social. The model is based on monthly cycles with half cycle corrections.

As $\mathrm{HF}$ is a life-long condition after onset, the model captured a life time horizon of 30 years with patients progressing through the model until they either died or reached the end of the 30-year time horizon. It was assumed that the interventions of STS, TM and standard care were provided for the full duration of the time horizon, outside of hospitalization. Both health system costs and QALYs were discounted at an annual rate of $5 \%$.

For the efficacy estimates, the monthly mortality probabilities were based on the 'Candesartan in Heart failure: Assessment of Reduction in Mortality and Morbidity' study. The mean number of HF related and other (all cause) hospitalizations were estimated from the published meta-analysis on the 'Economic impact of remote patient monitoring: An integrated economic model derived from a meta-analysis of randomized controlled trials in heart failure'. Hazard ratios were estimated from the network meta-analysis on 'Home telemonitoring or structured telephone support programmes after recent discharge in patients with heart failure'. Health state utilities for SC, STS and TM treatment approaches were based on the previous economic model of TM strategies of remote patient monitoring identified earlier. The units of resources making up the components of SC, STS and TM were based on the published literature, and unit costs were obtained from the Instituto Mexicano del Seguro Social.

\section{Bibliografía}

1. World Heart Federation. The Mexico Declaration. World Heart Federation; 2016. Available from: http://www.world-heartfederation.org/wcc-2016/the-mexico-declaration/

2. World Bank. World Development Indicators [Internet]; 2015. Available from: http://data.worldbank.org/topic [cited 12.09.15].

3. OECD. Health Statistics [Internet]. OECD iLibrary; 2015. Available from: http://www.oecd-ilibrary.org/social-issuesmigration-health/data/oecd-health-statistics/system-of-healthaccounts-health-expenditure-by-function_data-00349-en

4. Ministério da Saúde. Informações de Saúde [Internet]. DATASUS Tecnologia da Informação a Serviço do SUS; 2015. Available from: http://tabnet.datasus.gov.br/cgi/deftohtm. exe?sih/cnv/niuf.def [cited 05.09.15].

5. World Health Organization. Global Health Expenditures Database [Internet]; 2015. Available from: http://apps. who.int/nha/database/Select/Indicators/en [cited 10.06.15].

6. Vuong TD, Wei F, Beverly CJ. Absenteeism due to functional limitations caused by seven common chronic diseases in US workers. J Occup Environ Med. 2015;57:779-84.

7. Dennis C, Houston-Miller N, Schwartz RG, Ahn DK, Kraemer $\mathrm{HC}$, Gossard D, et al. Early return to work after uncomplicated myocardial infarction. Results of a randomized trial. JAMA. 1988;260:214.

8. Rohrbacker NJ, Kleinman NL, White SA, March JL, Reynolds MRi. The burden of atrial fibrillation and other cardiac arrhythmias in an employed population: associated costs, absences, and objective productivity loss. J Occup Environ Med. 2010;52:383-91.

9. Kruse M, Sørensen J, Davidsen M, Gyrd-Hansen DAT Short and long-term labour market consequences of coronary heart disease: a register-based follow-up study. Eur J Cardiovasc Prev Rehabil. 2009;16:387-91. Available from: http://cpr. sagepub.com/content/16/3/387. Abstract

10. Osler M, Mårtensson S, Prescott E, Carlsen K. Impact of gender, co-morbidity and social factors on labour market affiliation after first admission for acute coronary syndrome. A cohort study of Danish patients 2001-2009. PLoS ONE. 2014;9:e86758. Available from: https://www.ncbi.nlm.nih.gov/pubmed/ 24497976

Bryce Stevens ${ }^{a}$, Lynne Pezzullo ${ }^{a}$, Lara Verdian ${ }^{a}$, Josh Tomlinson ${ }^{a}$, Claudia Estrada-Aguilar ${ }^{a}$, Alice George ${ }^{a, *}$, Juan Verdejo-París ${ }^{b}$

\section{a Health Economics and Social Policy, Deloitte Access Economics Pty Ltd, Canberra, Australia}

\section{b Dirección de Enseñanza, Instituto Nacional de Cardiología, Mexico City, Mexico}

* Corresponding author at: 8 Brindabella Circuit, Canberra, ACT 2609, Australia. Tel.: +61262637278.

E-mail address: algeorge@deloitte.com.au (A. George).

https://doi.org/10.1016/j.acmx.2018.03.004

1405-9940/

(c) 2018 Instituto Nacional de Cardiología Ignacio Chávez. Published by Masson Doyma México S.A. This is an open access article under the CC BY-NC-ND license (http://creativecommons.org/licenses/ by-nc-nd/4.0/). 